\title{
The curse of wealth - Middle Eastern countries need to address the rapidly rising burden of diabetes
}

\author{
Lisa Klautzer ${ }^{1}$, Joachim Becker ${ }^{2}$, Soeren Mattke ${ }^{3, *}$
}

Abstract

The energy boom of the last decade has led to rapidly increasing wealth in the Middle East, particularly in the oil and gas-rich Gulf Cooperation Council (GCC) countries. This exceptional growth in prosperity has brought with it rapid changes in lifestyles that have resulted in a significant rise in chronic disease. In particular the number of people diagnosed with diabetes has increased dramatically and health system capacity has not kept pace. In this article, we summarize the current literature to illustrate the magnitude of the problem, its causes and its impact on health and point to options how to address it.

Keywords: Diabetes, Obesity, Health-Related Behavior, Metabolic Syndrome, Burden of Disease

Copyright: @ 2014 by Kerman University of Medical Sciences

Citation: Klautzer L, Becker J, Mattke S. The curse of wealth - Middle Eastern countries need to address the rapidly rising burden of diabetes. Int J Health Policy Manag 2014; 2: 109-114. doi: 10.15171/ijhpm.2014.33
Article History:

Received: 15 March 2014

Accepted: 31 March 2014 ePublished: 3 April 2014

\section{${ }^{*}$ Correspondence to:}

Soeren Mattke

Email: mattke@rand.org
Oil and gas exploitation has led to exceptional growth and prosperity

Three out of the world's top five oil exporting countries are located in the Gulf Cooperation Council (GCC) region ${ }^{1}$ (Saudi Arabia, UAE, and Kuwait ${ }^{2}$ ), as is the world's second largest exporter of natural gas (Qatar). The unprecedented demand ${ }^{3}$ and prices for oil and natural gas have catapulted these countries to join the richest economies in the world: with 90,524 US dollars, Qatar's GDP per capita, for example, surpassed in 2011 that of high-income OECD countries such as Switzerland, Sweden, and the United States with 83,326, 57,071, and 48,113 US dollars, respectively.

But prosperity comes at a price for public health

During the same time period, the GCC countries have experienced a marked rise in obesity and chronic disease prevalence. For example, the prevalence of obesity in adults of 30-60 years in Saudi Arabia increased by 1.5\% for women and 4.1\% for men annually between 1992 and 2005 (3). In Qatar and Kuwait, $35 \%$ and $36 \%$ of male; and $45 \%$ and $48 \%$ of female adults were found to be obese (3-5). Equally alarming are the numbers for younger age cohorts: In Kuwait, $21 \%$ of males and $18 \%$ of females aged $10-19$ were obese $(3,6,7)$.

1. The Gulf Cooperation Council (GCC), also known as the Cooperative Council for the Arab States of the Gulf, is a political and economic union of the following six countries bordering the Persian Gulf: Bahrain, Saudi Arabia, Kuwait, Qatar, the United Arab Emirates (UAE), and Oman.

2. According to the U.S. Energy Information Administration in 2012 the Top World Oil Net Exporters were Saudi Arabia, followed by Russia, UAE, Kuwait, and Nigeria (1).

3. Comparing the average annual consumption of natural gas for the 1990s and 2000 s with that of the 1980 s shows increases of $18 \%$ and $26 \%$ respectively (authors' calculation based on U.S. Energy Information Administration (EIA) (2), page 179, Table 6.1 Natural Gas Overview, Selected Years, 1949-2011 (Billion Cubic Feet).
In 2002, the WHO warned that obesity was an important determinant of health that could lead to adverse metabolic changes including increased levels of resistance to insulin and in turn raise the risk of type 2 diabetes mellitus (8). Accordingly, the rise in obesity in the GCC countries is likely to have substantially contributed to the rise of diabetes prevalence with an annualized rate of change of $4 \%$ in Saudi Arabia (between 1993 and 2000) and of 2\% in Oman (between 1991 and 2000) (3).

\section{Type 2 diabetes - a growing public health concern}

Such trends have led to type 2 diabetes becoming a major public health problem in the region. In 2012, four GCC countries (Kuwait, Saudi Arabia, Qatar, and Bahrain ${ }^{4}$ ) were among the 10 countries with the highest diabetes prevalence rates in the world $(9)^{5}$. While this paper focuses on GCC countries, as shown in Figure 1 below, the trend in the GCC follows that of the whole Middle East and North Africa (MENA) region ${ }^{6}$, where estimates for 2013 suggest approximately 34.6 million adults suffer from diabetes (9.2\% of the population), and an additional 25 million people (6.7\% of the population) are at high risk of developing diabetes from impaired glucose tolerance ${ }^{7}$. Even in less affluent countries, such as Egypt and Lebanon, the prevalence of diabetes is $17 \%$ and $15 \%$ respectively, and in low-income

\footnotetext{
4. The comparative prevalence numbers are calculated by assuming the same age profile (the age profile of the world population) for every country. This approach allows for appropriate comparison across countries by reducing the effect of age.

5. These numbers were based on diabetes in the population of 20-79 year olds.

6. The International Diabetes Federation (IDF) classification covers: Afghanistan, Algeria, Armenia, Bahrain, Egypt, Iran, Iraq, Jordan, Kuwait, Lebanon, Libyan, Morocco, Occupied Palestinian Territory, Oman, Pakistan, Qatar, Saudi Arabia, Sudan, Syrian, Tunisia, United Arab Emirates, and Yemen.

7. Impaired Glucose Tolerance (IGT) is a pre-diabetic state that has many common characteristics with type 2 diabetes (e.g. increased age and insulin resistance) and increases the risk of developing diabetes (10).
} 


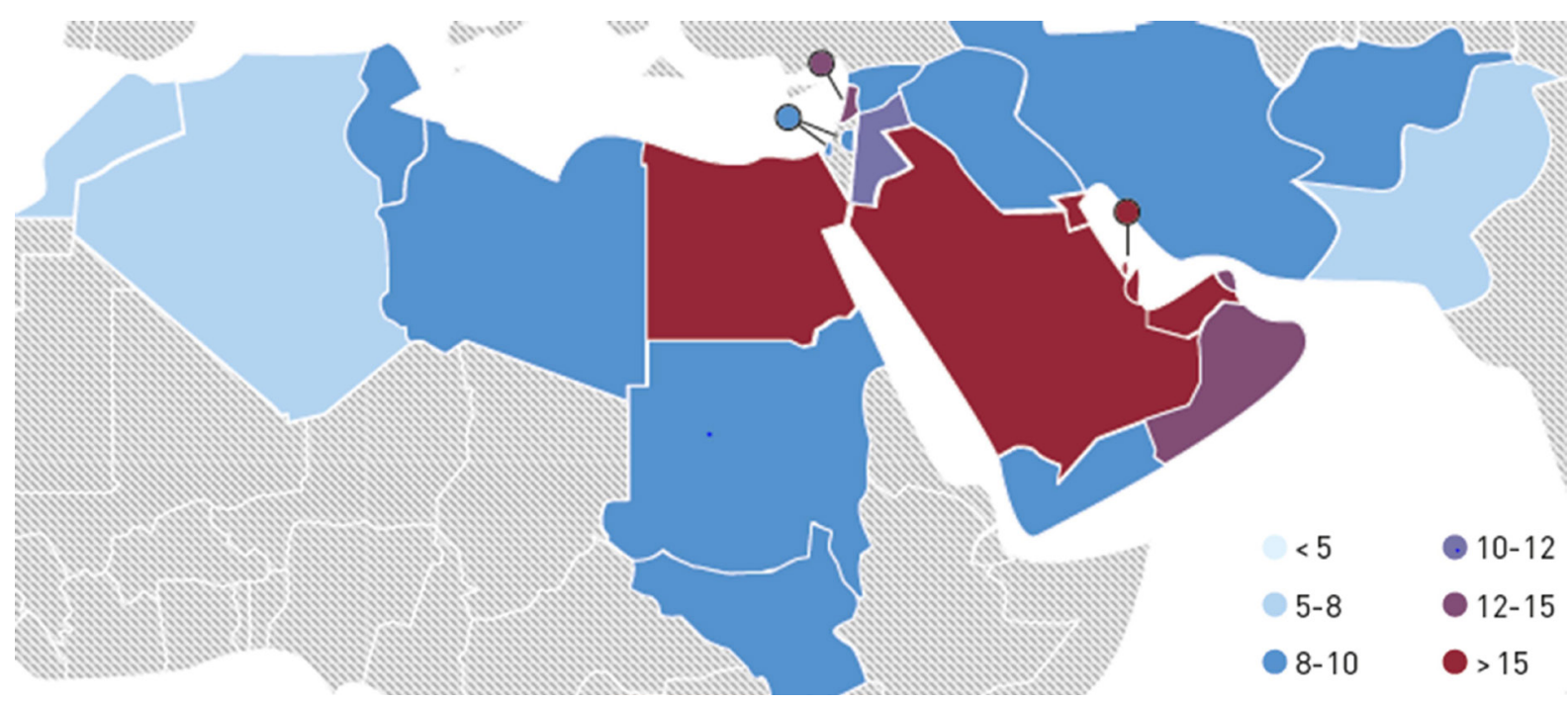

Figure 1. Comparative prevalence (\%) of diabetes in adults (20-79 years), 2013. Source: IDF 2013 (Map 3.3)

countries, such Sudan and Yemen, 8 to 10\% (10). The burden of diabetes is expected to surge over the next decades, as the Middle East will face the greatest increase in prevalence of type 2 diabetes worldwide, with 60 million diabetics in 2030 (11).

The high prevalence of diabetes contributes to mortality due to complications, including eye disease (retinopathy), kidney failure, vascular diseases such as myocardial infarction and stroke, and neuropathy. For example, diabetic men are twice and women four times as likely to suffer from Coronary Heart Disease (CHD); the risk of stroke increases by a factor of three and the risk of amputation by a factor of 25 , and diabetic retinopathy is the most common cause of blindness amongst 30-69 year olds (12).

Numbers for select GCC countries put the prevalence of diabetic retinopathy in diabetics at 14\% for Oman and 31\% for Saudi Arabia. Statistics from Saudi Arabia also illustrate the striking increase in lifetime risk for diabetics to require dialysis for end stage renal disease, from $4 \%$ in the early 1980 s to $40 \%$ in the late 1990s (13).

This diabetes epidemic is driven by a complex multitude of factors

This rise in chronic disease prevalence has been linked to a multitude of factors including dietary and lifestyle changes brought about by rapid economic development, increased urbanization, and the transition to a sedentary lifestyle (14).

\section{A shift towards more Western diets}

The dietary regime in the GCC region has moved away from "predominantly consuming dates, milk, fresh vegetables and fruit, whole wheat bread and fish to mostly foods rich in high saturated fats and refined carbohydrate diets coupled with a low dietary fiber intake" (13). In general, prosperity has led to greater consumption of meat; in Saudi Arabia for example, the per capita consumption of meat had increased on average by $2.2 \%$ per year between 1993 and 2003, while cereal consumption had declined during the same time period by an annual $0.1 \%$ (15). The proliferation of Western fast food chains may also have played a role in facilitating the dietary transition. Cultural norms have likely further reinforced the impact of this dietary transition: The hospitality culture where food is at the center of social interactions and refusing offered food could be seen as offensive to the host, and the fact that displaying some overweight is seen as a sign of wealth, exacerbate unhealthy nutrition patterns.

\section{Lower levels of physical activity}

Low levels of physical activity aggravate the impact of nutritional changes (Figure 2) (13). Decreased physical activity has likely been supported by greater availability of cars and mechanic appliances, cheap migrant workers, access to television, as well as computers and computer games. A more sedentary lifestyle may have been reinforced by cultural impediments to physical exercise and sports (e.g. requirement for women to be accompanied by a male family member and wear traditional dresses like abayas when going outside pose significant barriers to physical activity in some settings).

While the Quran encourages physical activities to take care of the body, the misinterpretation of the belief that "illness and wellness are God's will" may lead to fatalism with respect to health conditions $(16,17)$. Some regional health authorities have tried to engage the respective religious authorities, but even explicit support of healthy conduct does not guarantee the desired individual behavior. For example, in spite of a fatwa (a

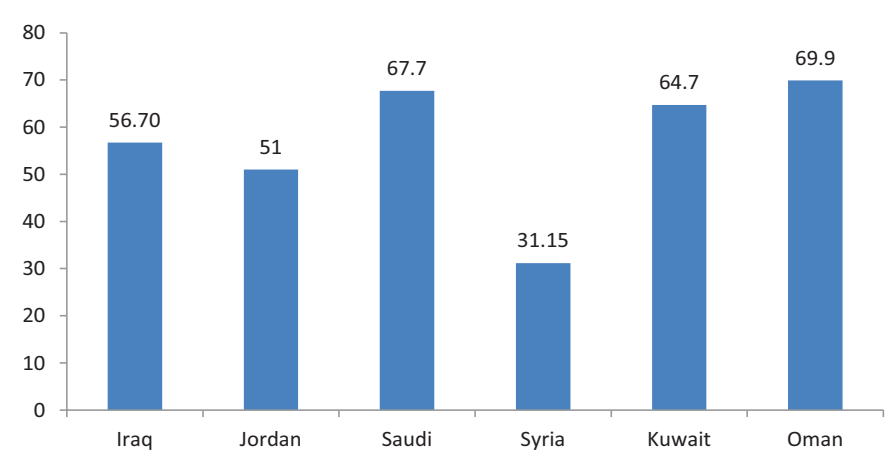

Figure 2. Percent of the population reporting low levels of daily exercise (daily activity $\leq 10 \mathrm{~min}$ ). Source: Badran and Laher (13) citing "STEPwise data from selected countries in the Eastern Mediterranean Region, 2003-2007", WHO EMRO. 
religious decree) exempting people with diabetes from fasting during Ramadan (17) about $81 \%$ of patients with type 1 diabetes and $94 \%$ of patients with type 2 diabetes were fasting at least 15 days during Ramadan, according to a multi-country study of 3,394 diabetics in 13 countries including the UAE and Saudi Arabia $(18)^{8}$.

The physical environment may also play a role; urban planning is often not supportive of physical activities and exercise facilities are frequently not available or expensive (20). In addition, climatic conditions present a major obstacle to outdoor activities, as Figure 3 illustrates.

\section{Genetic predisposition for diabetes}

Furthermore, Middle Eastern populations appear to have a higher genetic risk for diabetes (21). For example, a recent study of Middle Eastern immigrants in Sweden found that the immigrants had a two to threefold higher risk of type 2 diabetes than native Swedes (22).

In sum, there are many factors, from changes in activity and nutrition patterns to genetic predisposition that are likely to contribute to the high prevalence of type 2 diabetes in the GCC countries.

The current impact on the healthcare budgets is just the beginning

Diabetes represents a large burden on healthcare budgets

The International Diabetes Foundation (IDF) estimated that the MENA region spent 13.6 billion US dollars on diabetes care in 2013 (10). The countries with the highest spending per person with diabetes in 2013 in the region were the UAE, Qatar, Kuwait and Bahrain, with 2,228, 2,199, 1,886, and 905 US dollars, respectively (10). Under the current trajectory, the burden of the diabetes epidemic on Middle Eastern countries will continue to rise and put pressure on healthcare budgets, in particular if cases are diagnosed late and the opportunities of effective (and low cost) self-management are lost $(23,24)$. Based on current expenditure levels, the Health Authority-Abu Dhabi (HAAD), has forecast a nearly fourfold increase of healthcare cost for UAE nationals between 2010 and 2030 [HAAD (2011) based on Al-Maskari et al.] $(25,26)$.

Aggravating, the region has copied many flaws of the traditional Western healthcare system, concentrating on high-end curative rather than primary care and health promotion: 40-70\% of national healthcare budgets in most Arab countries are allocated to hospitals (27-30). This underinvestment in health promotion, prevention and primary care suggests the lack of a "medical home" $e^{9 "}$ - a healthcare delivery model that provides the continuous, integrated-, and comprehensive care that diabetes requires, in a more cost-effective way.

\section{GCC countries underinvesting in healthcare}

Despite their high levels of GDP per capita, the GCC countries underinvest overall in healthcare (see Figure 4). In 2011,

8. This confirms earlier findings of the EPIDIAR study (which included 12,243 diabetics from 13 Islamic countries) in which $43 \%$ of patients with type 1 diabetes and $79 \%$ of patients with type 2 diabetes were fasting at least 15 days during Ramadan (19).

9. A Patient-Centered Medical Home $(\mathrm{PCMH})$ "is a team-based model of care led by a personal physician who provides continuous and coordinated care throughout a patient's lifetime to maximize health outcomes" (31).
Kuwait, the UAE, and Qatar's per capita health expenditures were $1,500,1,640$, and 1,776 US dollars, respectively, compared to an average of 4,593 US dollars in OECD countries ${ }^{10}$ (32).

\section{Human resources for health are inadequate}

Additionally, human resources for health are not adequate and contribute to the fact that some GCC countries sent up to $10 \%$ of patients for emergency care treatments abroad (33). There are 10 physicians per 10,000 population in the Eastern Mediterranean Region ${ }^{11}$ compared with 32 in Europe and 19 in the Americas; and 15 nurses and midwives per 10,000 population compared to 79 in Europe and 49 in the Americas (30). A study in Saudi Arabia found that only $8 \%$ of primary healthcare centers were staffed with health educators - an important component in selfmanagement of chronic illnesses (34).

\section{As a result, quality of healthcare is suboptimal}

Ultimately, these factors are reflected in suboptimal quality of care; a recent systematic review of diabetes care in the GCC countries found that the management of type 2 diabetes based on the three major intermediate outcome measures (glycemic, blood pressure, and lipid control indicators) was suboptimal and that in almost all cases, less than $50 \%$ of patients met clinical outcomes targets (35). Too often primary care services are lagging particularly in providing appropriate diagnoses and referrals; according to Al-Ahmadi and Roland (34) "despite a high prevalence of diabetic retinopathy, only $40-68 \%$ of diabetic patients (in Saudi Arabia) were referred to eye clinics". Reasons for this sub-optimal diabetes management are manifold and include next to the underfunding, primary care physicians that are often not trained to deal with diabetes, diabetes educators that are rarely reimbursed or evaluated based on their results, and the lack of specialized training and certification of diabetes educators. This situation will be further challenged considering that a McKinsey study projected a 323\% increase in treatment demand for diabetes-related ailments in the GCC countries by 2025 (36).

\section{But awareness of the problem is rising in the region}

The good news is that awareness of non-communicable diseases (in particular diabetes) is rising in the region. Acknowledging predicted 1.2 billion US dollars in direct health costs for UAE nationals diabetes treatment in 2030 [HAAD (2011) based on Al-Maskari et al.] $(25,26)$, the Health Authority Abu Dhabi (HAAD), the largest of the UAE's emirates, has, for example, started to screen all adult citizens for cardiovascular risk factors as a requirement for enrollment into free health insurance. This initiative, called Weqaya, has revealed that about $45 \%$ of the screened population had diabetes or pre-diabetes (25). HAAD intends to use the findings to educate citizens about health risks and to direct them to disease management programs ${ }^{12}$.

10. Based on per capita health expenditures (current US dollar) for 2011 from the World Bank's World Development Indicators (2013).

11. The WHO classification covering: Afghanistan, Bahrain, Djibouti, Egypt, Iran, Iraq, Jordan, Kuwait, Lebanon, Libya, Morocco, Oman, Pakistan, Qatar, Saudi Arabia, Somalia, South Sudan, Sudan, Syrian Arab Republic, Tunisia, UAE, and Yemen.

12. Of note is also that although many GCC countries have a large expatriate population (often composed by a smaller share of western knowledge workers and a significantly larger share of low paid nationals from developing countries 


\begin{tabular}{|c|c|c|c|c|c|c|c|c|c|c|c|c|}
\hline & Jan & Feb & Mar & Apr & May & Jun & Jul & Aug & Sep & Oct & Nov & Dec \\
\hline Qatar & & & & 34.4 (94 F) & 41.6 (107 F) & $46.1(115 \mathrm{~F})$ & $50.5(123 \mathrm{~F})$ & 56.6 (134 F) & $51.6(125 \mathrm{~F})$ & $41(106 \mathrm{~F})$ & $30(86 \mathrm{~F})$ & \\
\hline Bahrain & & & & $32.2(90 \mathrm{~F})$ & 42.2 (108 F) & 47.7 (118 F) & $53.8(129 \mathrm{~F})$ & $57.2(135 \mathrm{~F})$ & $53.5(128 \mathrm{~F})$ & 41.6 (107 F) & $28.8(84 \mathrm{~F})$ & \\
\hline Kuwait & & & & $35(95 \mathrm{~F})$ & 53.8 (129 F) & $58.3(137 \mathrm{~F})^{*}$ & 58.3 (137 F) & $58.3(137 \mathrm{~F})$ & 57.7 (136 F) & 43.8 (111 F) & & \\
\hline Oman & & & $30(86 \mathrm{~F})$ & $35.5(96 \mathrm{~F})$ & 41 (106 F) & 41.6 (107 F) & $39.4(103 \mathrm{~F})$ & 41.6 (107 F) & $41(106 \mathrm{~F})$ & 38.3 (101 F) & $31.6(89 \mathrm{~F})$ & \\
\hline Saudi Arabia & & & & 35.5 (96 F) & 48.3 (119 F) & $51.1(124 \mathrm{~F})$ & 57.2 (135 F) & $58.3(137 \mathrm{~F})$ & $52.7(127 \mathrm{~F})$ & $42.7(109)$ & $28.8(84 \mathrm{~F})$ & \\
\hline ited Arab Emirates & & & $29.4(85 F)$ & 36.1 (97 F) & 44.4 (112 F) & 56.6 (134 F) & 57.2 (135 F) & $58.3(137 \mathrm{~F})$ & 58.3 (137 F) & $45.5(114)$ & 32.2 (90 F) & \\
\hline
\end{tabular}

*Note: 58.3 (137 F) is the scale max

\begin{tabular}{|l|l|l|l|l|}
\hline & & & & \\
\hline No danger & Caution & $\begin{array}{c}\text { Extreme } \\
\text { Caution }\end{array}$ & Danger & $\begin{array}{c}\text { Extreme } \\
\text { Danger }\end{array}$ \\
\hline
\end{tabular}

Figure 3. Heat index in Persian Gulf Countries (danger levels according to NOAA). Source: Authors' analysis based on danger levels according to the National Oceanic Atmospheric Administration (NOAA)'s National Weather Service's Heat Index Chart (Available at: http://www.nws.noaa.gov/os/ heat/index.shtml).

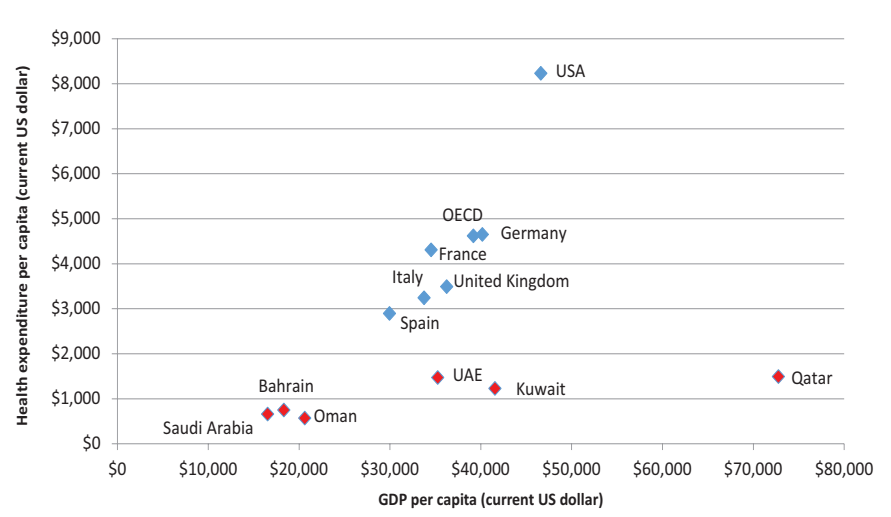

Figure 4. Per capita GDP and health expenditures in the high-income Middle Eastern countries relative to high-income OECD countries (2010). Source: World Development Indicators 2013.

\section{The opportunity for advanced diabetes services}

This mismatch between the growing demand for diabetes care and the inadequate setup of local healthcare systems in the GCC countries implies the need for creative solutions. Beyond cross-sectoral health promotion efforts to curb obesity and related non-communicable diseases (37-39) including the framing of specific diabetes policies and action plans, there are opportunities for health insurers, investors (e.g. sovereign wealth funds and venture capitalists), pharmaceutical companies, and healthcare delivery organizations to fill the gap by providing integrated care across the full continuum of patient needs in dedicated diabetes centers ${ }^{13}$.

Such centers could capture the whole care continuum from pre-diabetes to severe cases with end-organ damage under one roof, providing patients with convenient access to all related services while allowing for the volume necessary to realize

who work in particular in the construction and service sector) many local health initiatives and public health systems cover only nationals.

13. Some first movers in a similar direction have already emerged such as Abu Dhabi's Imperial College London Diabetes Centre (ICLDC) established in 2006 as a joint venture between Mubadala Healthcare (funded by the government of Abu Dhabi) and Imperial College. The ICLDC has since opened a second site in AI Ain. economies of scale (see Figure 5). The centers would have a strong primary care component to promote early detection, tailored education, optimal self-management, and successful counseling on lifestyle changes. Centers would adopt a holistic approach integrating a team of diabetes educators, specialized nurses, dietitians, exercise physiologists, and psychologists, and social workers into the process. These would be complemented by specialty care offering comprehensive clinical services including cardiology, eye care, endocrinology, nephrology, and dialysis. For those cases that nonetheless require tertiary care, the centers would establish a network of affiliated hospitals. Finally, pharmacy and medication management services would be addressed by the center and allow for treatment optimization. Services would be provided in a manner consistent with local norms and attitudes, such as on gender roles, views on physical activity, and dietary habits.

This design, building on state of the art knowledge, recognizes that diabetic complications like blindness, kidney failure, nerve damage, amputations, strokes or heart disease are not inevitable. These complications and their healthcare costs and societal $\operatorname{cost}^{14}$, can be significantly reduced or avoided. Such an evidence-based and holistic approach is more likely to also honor the tradition of Arab healers who have a long history of being guided by science rather than dogma. As early as in medieval times, when blood-letting was the standard of care in Europe, Arab medicine experimented with herbal remedies, developed surgical tools to perform operations, used animals to test the effects of substances, and built upon their knowledge of the human body (40).

Innovative payment schemes such as risk-adjusted capitation, gain-sharing models and pay-for-performance schemes based on health outcomes could be established. This would

14. Al-Maskari et al. (26) found that in their sample the direct treatment cost of patients with diabetes was 3.2 times higher than the per capita expenditure for healthcare in the UAE, and that these cost increased by 2.2 times for patients with diabetes-related microvascular complications; by 6.4 times for patients with diabetes-related macrovascular complications; and by 9.4 times for patients with both micro and macrovascular diabetes-related complications. This illustrates the steep increase of health expenditures when early intervention and selfmanagement are not successful and complications occur. 


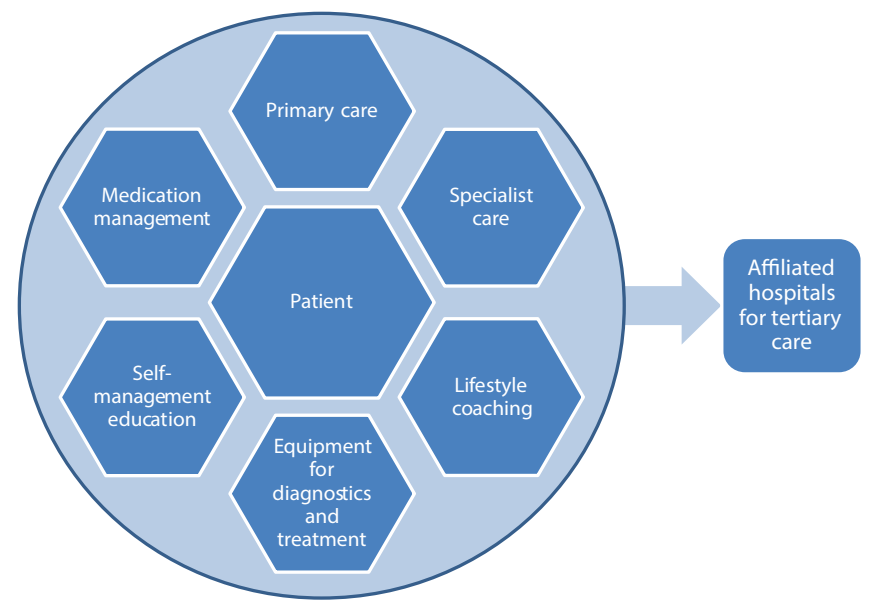

Figure 5. Integrated diabetes care model for free-standing centers

allow payers to share gain from optimized management with integrated diabetes centers. Such an approach should not only result in cost savings, but also in substantive improvements to the quality of life of patients.

The need for innovation is clear. And while these centers could have a major impact on improving diabetes care, there is obviously a range of specific policies that would have to accompany any successful strategy to tackle diabetes in the region. These include research in particular with respect to people's motivations and behaviors to understand how to effectively communicate and drive the needed move towards a healthier lifestyle, dedicated financial support for high quality primary healthcare, training, licensing and design of attractive and outcome oriented compensation of diabetes educators, and last but not least dedicated and visionary leadership.

Ethical issues

Not applicable.

\section{Competing interests}

The authors declare that they have no competing interests.

\section{Authors' contributions}

LK was the lead in reviewing the literature, gathering the data, and drafting the manuscript. JB contributed to the literature review, reviewed the paper, and provided invaluable contextual insights on the challenges to addressing the diabetes epidemic in Middle Eastern countries. SM initiated the idea, reviewed the paper, and provided guidance throughout the process. All authors reviewed and approved the final manuscript.

\section{Authors' affiliations}

${ }^{1}$ Pardee RAND Graduate School, Santa Monica, CA, USA. 'Diabetes Strategy - Emerging Markets at Eli Lilly and Company. ${ }^{3}$ RAND Health Advisory Services, RAND Corporation, Boston, MA, USA

\section{References}

1. U.S. Energy Information Administration (EIA). Top World Oil Net Exporters, 2012 (Thousand Barrels per Day) [internet]. 2013 [updated 2013 August 16]. Available from: http://www.eia.gov/ countries/index.cfm?topL=exp

2. U.S. Energy Information Administration (EIA). Annual Energy Review 2011. Washington, DC: EIA; 2012.

3. Ng SW, Zaghloul S, Ali HI, Harrison G, Popkin BM. The prevalence and trends of overweight, obesity and nutrition-related noncommunicable diseases in the Arabian Gulf States. Obes Rev 2011; 12: 1-13.

4. Al-Nesf Y, Kamel M, El-Shazly MK, Makboul GM, Sadek AA, ElSayed AM, et al. Kuwait STEPS 2006. Kuwait Ministry of Health,

\section{GCC, WHO; 2006.}

5. Bener A, Al-Suwaidi J, Al-Jaber K, Al-Marri S, Dagash MH, Elbagi $\mathrm{IE}$. The prevalence of hypertension and its associated risk factors in a newly developed country. Saudi Med J 2004; 25: 918-22.

6. Kuwait Ministry of Health (MoH). Kuwait Nutrition Surveillance (2001-2004). Food and Nutrition Administration (ed.). Kuwait: Ministry of Health: 2004.

7. Al-Sendi AM, Shetty P, Musaiger AO. Prevalence of overweight and obesity among Bahraini adolescents: a comparison between three different sets of criteria. Eur J Clin Nutr 2003; 57: 471-4.

8. World Health Organization (WHO). The World Health Report 2002: Reducing Risks, Promoting Healthy Life. Geneva: WHO; 2002.

9. International Diabetes Foundation (IDF). Diabetes Atlas. 5th edition (updated) [internet]. 2012. Available From: http://www.idf.org/sites/ default/files/5E_IDFAtlasPoster_2012_EN.pdf

10. International Diabetes Federation (IDF). Diabetes Atlas. 6th edition [internet]. 2013. Available from: http://www.idf.org/sites/default/ files/EN 6E Atlas Full 0.pdf

11. Habibzadeh F. Diabetes in the Middle East. Lancet 2012; 380: 1.

12. van Dieren S, Beulens JW, van der Schouw YT, Grobbee DE, Neal B. The global burden of diabetes and its complications: an emerging pandemic. Eur J Cardiovasc Prev Rehabil 2010; 17: S3-8.

13. Badran M, Laher I. Type II Diabetes Mellitus in Arabic-Speaking Countries. Int J Endocrinol 2012; 2012: 902873.

14. World Health Organization (WHO). Global status report on noncommunicable diseases 2010. Geneva: WHO; 2011.

15. National Commercial Bank (NCB) Capital. GCC Agriculture: Bridging the food gap. Economic Research [internet]. March 2010. Available from: http://www.gulfbase.com/ScheduleReports/GCC_ Agriculture_Sector_March2010.pdf

16. Yosef AR. Health Beliefs, Practice, and Priorities for Health Care of Arab Muslims in the United States Implications for Nursing Care. J Transcult Nurs 2008; 19: 284-91.

17. Alzaid A. Diabetes: A tale of two cultures. Br J Diabetes Vasc Dis 2012; 12: 57.

18. Babineaux S, Miller L, Courtinard C, Toaima D, Tahbaz A, Zagar A, et al. An Epidemiological Study of the Lifestyle and Treatment Changes in Patients With Diabetes Before Initiation of Ramadan Fasting Period. International Diabetes Federation (IDF) 21st World Diabetes Congress; December 4-8, 2011; Dubai, UAE.

19. Salti I, Bénard E, Detournay B, Bianchi-Biscay M, Le Brigand C, Voinet $\mathrm{C}$, et al. EPIDIAR study group A population-based study of diabetes and its characteristics during the fasting month of Ramadan in 13 countries: results of the epidemiology of diabetes and Ramadan 1422/2001 (EPIDIAR) study. Diabetes Care 2004; 27: 2306-11.

20. Benjamin K, Donnelly TT. Barriers and facilitators influencing the physical activity of Arabic adults: A literature review. Avicenna 2013; 8: 1-16.

21. Meyer BF, Alsmadi O, Wakil S, Al-Rubeaan K. Genetics of type 2 diabetes in Arabs: What we know to date. Int $J$ Diabetes Mellit 2009; 1: 32-4.

22. Ahlqvist E, Ahluwalia TS, Groop L. Genetics of type 2 diabetes. Clin Chem 2011; 57: 241-54.

23. World Health Organization (WHO). Diabetes: the cost of diabetes [internet]. Undated. Available from: http://www.who.int/ mediacentre/factsheets/fs236/en/\#

24. Williams R, Van Gaal L, Lucioni C. Assessing the impact of complications on the costs of Type II diabetes. Diabetologia 2002; 45: S13-7.

25. Health Authority - Abu Dhabi (HAAD). Weqaya [internet]. 2011. Available from: http://www.who.int/tobacco/mhealth/weqaya.pdf

26. Al-Maskari F, El-Sadig M, Nagelkerke N. Assessment of the direct medical costs of diabetes mellitus and its complications in the United Arab Emirates. BMC Public Health 2010: 10: 679.

27. Kronfol NM. Delivery of health services in Arab countries: a review. East Mediterr Health J 2012; 18: 1229-38.

28. Makhoul J, El-Barbir F. Obstacles to health in the Arab world. BMJ 2006; 333: 859.

29. Akala FA, El-Saharty S. Public-health challenges in the Middle East and North Africa. Lancet 2006; 367: 961-4. 
30. Ghannem $\mathrm{H}$. The need for capacity building to prevent chronic diseases in North Africa and the Middle East. East Mediterr Health J 2011; 17: 630-2.

31. American College of Physicians [homepage on the Internet]. [updated 2013 December 16]. Available from: http://www.acponline. org/running_practice/delivery_and_payment_models/pcmh/

32. The World Bank. World Development Indicators [homepage on the Internet]. [updated 2013 December 18]. Available from: http://data. worldbank.org/data-catalog/world-development-indicators

33. Informa. Healthcare in the GCC: A Snapshot. Hospital Build \& Infrastructure Magazine [serial on the Internet]. 2012. Available from: http://inc.iirme.com/Sites/HospitalBuild/v1/Downloads/resources/ articles/Regional\%20healthcare/regional_healthcare.pdf

34. Al-Ahmadi H, Roland M. Quality of primary health care in Saudi Arabia: a comprehensive review. Int J Qual Health Care 2006; 17: $331-46$.

35. Alhyas L, McKay A, Balasanthiran A, Majeed A. Quality of type 2 diabetes management in the states of the Co-operation Council for the Arab States of the Gulf: a systematic review. PLoS One 2011; 6: e22186.

36. Mourshed M, Hediger V, Lambert T. Gulf Cooperation Council Health Care: Challenges and Opportunities [internet]. 2008. Available from: http://www.weforum.org/pdf/Global_Competitiveness_Reports/ Reports/chapters/2 1.pdf

37. World Health Organization (WHO). Global Strategy on Diet, Physical Activity and Health. Geneva: WHO; 2004.

38. World Health Organization (WHO). European Action Plan for Food and Nutrition Policy 2007-2012. Geneva: WHO; 2008.

39. World Health Organization (WHO). World Health Assemblyendorsed the Global NCD Action Plan 2013-2020. Geneva: WHO; 2013.

40. Saad B, Azaizeh $\mathrm{H}$, Said O. Tradition and perspectives of arab herbal medicine: a review. Evid Based Complement Alternat Med 2005; 2: 475-9. 